\title{
The Impact on Private Customization of Network Information
}

\author{
Xinting Liu, Lu Shen* \\ ${ }^{1}$ School of Journalism and Mass Communication, Nanchang University, Nanchang, Jiangxi, China \\ *Corresponding Author.
}

\begin{abstract}
:
In the era of new media, private customization of network information is widespread, which has affected the development process of individuals and society. The previous research on private customization of network information focused on algorithm research, which mostly starts from the micro analysis such as news products, entertainment products, social products and so on. This paper uses qualitative analysis and in-depth interviews with users based on their use of various apps to explore the behavioral and psychological. Through the information obtained from in-depth interviews, the results are as follows: Private customization of network information helps individuals break through the load of information, but brings personal loss. Customization technology of network information has the problem of technology supremacy to restrict personal freedom and power. In addition, it is also worth thinking about the problem of the construction of public areas. Through the discussion of this macro impact, a comprehensive explanation can be obtained. These findings of the research indicate that the macro impact of private customization of network information is not just the responsibility of the information provider, but also do the audiences, government and industry departments need to think about together. Only when it abides by the social benefits, can it achieve sound progress.
\end{abstract}

Keywords: Network information, Private customization, Personal Freedom, Public Areas.

\section{INTRODUCTION}

In the Internet age, people are in the flood of information all the time, with the popularization of smart phones and the development of communication technology. Surfing the Internet through mobile phones and PCS has become an essential part of people's life. In this context, customization technology has become a routine way for many apps and websites to send information, such as the application of big data analysis, algorithm mechanism and artificial 
intelligence to filter information and make personalized recommendation. Personalized network information services, tailor-made web information services, were pioneered by Amazon and Google in the field of search engine.

Domestic and foreign media use different algorithm modes to capture users' behaviors and Interests, to match and push customized information content based on collaborative filtering, content, heat, etc [1].Personal customization of network information forms "personal daily newspaper" service which proposed by Negroponte in Digital Survival [2]. When we see "featured", "local", "Guess what you like", "recommended of the day" and other content on mobile phones, is it really what we like and need, what impact does such services have on individuals, and what does it bring to society?

\section{METHODS}

As a research focusing algorithm customization, it is different from previous studies. First of all, previous studies are more from the perspective of communicators, and the audience is passive. This paper advances the view that audience also have right. Secondly, the previous research mostly adopts quantitative method. This paper uses qualitative analysis and in-depth interviews with users based on their use of various apps to explore the behavioral and psychological.

In order to fully understand the impact of information customization, this paper records the common apps' push methods and procedures when they customize information. Then, twenty people of different ages were selected. This paper conduct an in-depth interview on their use of APPs.

\section{RESULTS AND DISCUSSION}

3.1 Break through the Personal Loss under the Information Load

Facing the full of beautiful things in eyes and abundant network information "buffet", our capacity limited to select information by ourselves. At this moment, customized information to their "preference" can efficiently process information data, help the audience to simplify information retrieval, save the audience's choice time for accurate reading, reduce the load of personal information, and optimize the reading experience.

If everyone's field of interest is a circle, people can constantly expand the scope of their own circle through personal customization, but they have limited time and energy to access information outside the circle. When other types of knowledge increase rapidly, they do not 
know themselves, but "know less". They gradually falling into a paradox of knowledge - seemingly "well-informed", but actually "ignorant" [3]. In the end, people can only make judgments and choices in life based on the information obtained in the circle, and cannot develop new interests, so that personal habits and thinking interests are solidified, and get lost in the circle of self, resulting in cognitive degeneration. The result is the "echo chamber" effect mentioned by Sunstein in the book "Internet Republic". "The limitations of the 'echo chamber' tend to make individuals more extreme, narrow-minded and blindly confident." [4] "Information narrowing" and "filter bubbles" all illustrate this.

At the same time, the audience also has the psychology of "curiosity" and "control". What the audience cares about is the right to choose all the information content anytime and anywhere, or occasionally want to change a taste [5]. The personal customization with only one or several options makes the audience lose the right of comprehensive choice from the original, which makes it easy to read anxiety and fatigue. When some audiences with independent thinking ability are kidnapped by these information systems with single content, high similarity, biased view and obvious persuasion intention, they will also distrust the push media, then they have compulsive feelings and psychological resistance.

In addition, algorithm-based push is also accidental and experiential. The audience does not know what they want sometimes in fact. Once the cold start or the occasional behavior is recorded, it will be misread and abused.

\subsection{The Issue of Personal Freedom under the Discussion of Technology Security}

Sunstein is concerned about the potential crisis of "personal daily newspaper" under the technology and consumer freedom, putting forward the concept of an "echo chamber" effect. Therefore, we can consider the impact of private customization from both technology and consumption.

To achieve precise push of customization, the prerequisite is to extract basic demographic factors, continuously record and revise the user's interests. People who use apps often have the experience of having to choose whether to log in in another way to access basic information, or select tourists to $\log$ in, or at least one interested channel. In many cases, users are required to sign the permission to obtain personal information such as location and address book. Compulsory and excessive claim of authority, collection of personal information has become a threat to personal privacy. This leads to the problem of user information security and the discussion about social ethics. Network information customization unscrupulously does not respect personal privacy [6].If the technical security is not in place, scattered personal 
information will be mined and analyzed. Once the data is associated, the audience's personal trends and information will be grasped, just like living under the camera at any time, or even endangering the security of their property.

In addition to the privacy debate, technology has also brought a battle over copyright. In China, most clients that customize personalized information for the audience are information technology companies taking news client as an example. Nowadays, Headline, ZAKER and Tian-tian-Kuai do not produce content independently, but aggregate other information focusing on better tillage algorithm and completion of push. In this way, different market subjects will deteriorate and push competition instead of content competition. The platform will be sought after by the market, while the labor of information creators will be ignored, which will affect the social innovation mood. Moreover, many customized information is pushed with violence, the entertainment and sex as the profit criteria that users tend to like such as controversial and stimulating information. And the population exposed to the Internet is becoming younger and younger, even adults can be influenced by unhealthy information to lead lifestyles and behaviors that they cannot understand.

The audience is immersed in the pleasure of personal customization based on the algorithm technology. It does not require much effort to screen information, causing many people to habitually stop thinking deeply. However, technology control is ultimately self-control. That is to say, the impact of personal customization on personal development varies from person to person, depending on different people's habits of using communication tools, interaction frequency of social communication and interpersonal communication, and decoding ability of information. Audiences with low media literacy are prone to indulge in "information cocoons" and become slaves of technology, resulting in less time for social communication, lacking critical thinking and action ability.

Audiences use customized technology to better monitor the environment, guide practice, and process information more freely and smoothly in the face of change. But they can't see the new things, so it is difficult to produce new desire. Without diversified information input, the omission of major news events will affect the effective judgment of individual decision making. If you limit yourself too much, you lose the right to choose and know, so that the right to freedom can't be realized.

\subsection{The Foundation and Obstacle Construction of Public Domain Construction}

Sunstein argues that "personal daily newspaper" has created "information cocoons" in his book Democracy and Internet, which many scholars have on the affirmation and the further 
research. They generally agree that whether the information cocoons occur customized information before or after, customized information has a certain impact on people's "information cocoons". Based on "information cocoons", "values cocoon", "group polarization" and "public opinion guidance digestion" are generated, which will erode the construction of social public sphere.

One of construction of social public sphere — democratic communication, requires a certain degree of consensus and is accomplished through consultation mechanisms. It is undeniable that personalized customization accelerates the formation of groups through accurate sharing of information. However, groups are unwilling to accept diversified views under the individual "information cocoons" and group will, which weakens the possibility of understanding and empathizing with other groups and forms communication barriers between social groups. If other voices are ignored, a rational, exoteric and inclusive public space cannot be formed, which increases the difficulty of dialogue between different groups. Private customization of network information strengthens the "information cocoons" and weakens the social stickiness [7].Social groups cannot share experience and communicate with each other, so social problems are difficult to be solved.

When personal interest is higher than public interest, private customization will ignore public issues for a long time, making the audience lose the scope of attention and sensitivity to participate. Even if there are public issues, they are presented in an entertaining way. Customizers serve the personal interests, forming and expressing the practical logic and disclosing the publicity of social problems. It becomes water without a source. Only set private topics, the audience will regard private topics as hot topics, but there is no time to publish, participate in and interact with the real mainstream topics. In the long run, the sound public opinion is affected.

\section{CONCLUSION}

Based on in-depth interview and information customization practice of app, this paper explores that Internet information customization has brought positive and negative contradictory effects. These results suggest that the audience is willing to accept private customization of information, but they hope their individual rights are respected. Meanwhile, the construction of public sphere needs private customization of information, but the provides should pay attention to public topics and have "public spirit". Complexity gives way to person. [8].The distribution logic of Internet thinking is that rationality gives way to emotion or is "people" value higher than "user" value. It determines the "good" and "evil" of individuals and society in the form of private 
customization.

These results have great enlightenment for everyone and every organization. How to assume their respective responsibilities is a problem that information providers, audiences, government and industry departments need to think about together.

Although this paper's investigation provides first-hand information and in-sight into the impact on private customization of network Information, more case studies and long-term research are needed to enhance the generalizability of the findings. Further studies should also be combined with quantitative analysis. The research methods in this paper are few and the scope of the study is limited, but it gives new attention perspective, which shows practical values.

\section{REFERENCES}

[1] Xu YF (2018) "Information Cocoon" effect and reflection of algorithm recommendation. News Research Guide, 9(14):42-43.

[2] Nicholas Negroponte, Being digital, Hu Yong trans. Beijing: Electronic Industry Press, 2017, pp.4.

[3] Wang YW (2018) The influence of news customization in the era of recommendation. Communication and Copyright, 6(3):4-5.

[4] Cass R. Sunstein (2001) Democracy and the Internet, Princeton: Princeton University Press pp.224.

[5] Xiong ZZ (2015) Do users really need to customize news? Reporter, 33(4):42-46.

[6] Zhao CG (2017) On the Ethical Problems in News Content Customization. Editors' Friend 37(9): 49-52.

[7] Wang G (2017) Reflection on the "Information Cocoon" effect under the model of "Personal Daily". Youth Journalist, 77(10):18-19.

[8] Yu GM, Qu H (2019) The Misreading of "Information Cocoon" and the Necessity of Algorithm Push: On the Solution to the Social Ethical Dilemma in Content Distribution. Journal of Xinjiang Normal University (Philosophy and Social Science) 41(1):128-133. 